\title{
Evaluating Global Warming Potentials with historical temperature
}

\author{
Katsumasa Tanaka • Brian C. O'Neill • \\ Dmitry Rokityanskiy • Michael Obersteiner • \\ Richard S. J. Tol
}

Received: 11 October 2006 / Accepted: 26 December 2008 / Published online: 1 April 2009

(C) Springer Science + Business Media B.V. 2009

K. Tanaka $(\varangle)$ · Brian C. O’Neill · D. Rokityanskiy · M. Obersteiner · R. S. J. Tol International Institute for Applied Systems Analysis (IIASA),

Schlossplatz 1, 2361 Laxenburg, Austria

e-mail: tanaka@iiasa.ac.at

K. Tanaka

Research Unit Sustainability and Global Change, University of Hamburg,

Hamburg, Germany

K. Tanaka

International Max Planck Research School on Earth System Modelling (IMPRS-ESM),

Hamburg, Germany

B. C. O'Neill

National Center for Atmospheric Research (NCAR), Boulder, CO, USA

D. Rokityanskiy

Russian Academy of Sciences, Moscow, Russia

R. S. J. Tol

Economic and Social Research Institute, Dublin, Ireland

R. S. J. Tol

Institute for Environmental Studies, Vrije Universiteit, Amsterdam, The Netherlands

R. S. J. Tol

Department of Spatial Economics, Vrije Universiteit, Amsterdam, The Netherlands

R. S. J. Tol

Department of Engineering and Public Policy, Carnegie Mellon University,

Pittsburgh, PA, USA 
Abstract Global Warming Potentials (GWPs) are evaluated with historical temperature by applying them to convert historical $\mathrm{CH}_{4}$ and $\mathrm{N}_{2} \mathrm{O}$ emissions to equivalent $\mathrm{CO}_{2}$ emissions. Our GWP analysis is based on an inverse estimation using the Aggregated Carbon Cycle, Atmospheric Chemistry, and Climate Model (ACC2). We find that, for both $\mathrm{CH}_{4}$ and $\mathrm{N}_{2} \mathrm{O}$, indices higher than the Kyoto GWPs (100year time horizon) would reproduce better the historical temperature. The $\mathrm{CH}_{4}$ GWP provides a best fit to the historical temperature when it is calculated with a time horizon of 44 years. However, the $\mathrm{N}_{2} \mathrm{O}$ GWP does not approximate well the historical temperature with any time horizon. We introduce a new exchange metric, TEMperature Proxy index (TEMP), that is defined so that it provides a best fit to the temperature projection of a given period. By comparing GWPs and TEMPs, we find that the inability of the $\mathrm{N}_{2} \mathrm{O}$ GWP to reproduce the historical temperature is caused by the GWP calculation methodology in IPCC using simplifying assumptions for the background system dynamics and uncertain parameter estimations. Furthermore, our TEMP calculations demonstrate that indices have to be progressively updated upon the acquisition of new measurements and/or the advancement of our understanding of Earth system processes.

\section{Introduction}

Global climate change during the Anthropocene (Crutzen 2002) is largely triggered by the human-driven perturbation of the atmospheric composition of various radiative agents. These agents have different physical and biogeochemical properties, interfering with the Earth system distinctively. Due to the complexities and uncertainties in the Earth system processes, finding a common ground to compare different GreenHouse Gas (GHG) emissions is a challenging task. As a simple measure, the concept of Global Warming Potentials (GWPs) has been introduced. The GWP of a particular GHG is defined as the ratio of the integrated radiative forcing of the GHG over a time horizon to that of $\mathrm{CO}_{2}$ after their instantaneous releases to the atmosphere in the amounts of $1 \mathrm{~kg}$ (IPCC 1990). GWPs are used to convert the emissions of non- $\mathrm{CO}_{2}$ GHGs to 'equivalent' $\mathrm{CO}_{2}$ emissions, allowing policy-makers to consider and compare multiple options for $\mathrm{GHG}$ emission reduction.

However, since the conception of GWPs, they have been a subject of dispute in the research community (Fuglestvedt et al. 2003). One fundamental shortcoming in the concept of GWPs is the arbitrariness in the length of the time horizon over which to integrate the radiative forcings. Time horizons of 20, 100, and 500 years are representatively used in Table 6.7 of IPCC (2001). ${ }^{1}$ A time horizon of 100 years is selected for the GWPs implemented in the Kyoto Protocol without any clear scientific argumentation. Generally, for a GHG with a lifetime shorter than that of $\mathrm{CO}_{2}$, the GWP will be larger for shorter time horizons, although this comparison is complicated by the range of timescales with which $\mathrm{CO}_{2}$ is removed (O'Neill et al. 1997). Figure 1a, b show the GWPs of $\mathrm{CH}_{4}$ and $\mathrm{N}_{2} \mathrm{O}$ for time horizons of 0-500 years, calculated using the lifetimes and other parameter values given in Table 1. Various

\footnotetext{
${ }^{1}$ We evaluate the GWPs shown in IPCC (2001, Table 6.7). The values of GWPs have been slightly changed in IPCC (2007, Table 2.14) because a different $\mathrm{CO}_{2}$ response function has been employed. However, these changes are minor and there would be no change in our conclusions.
} 

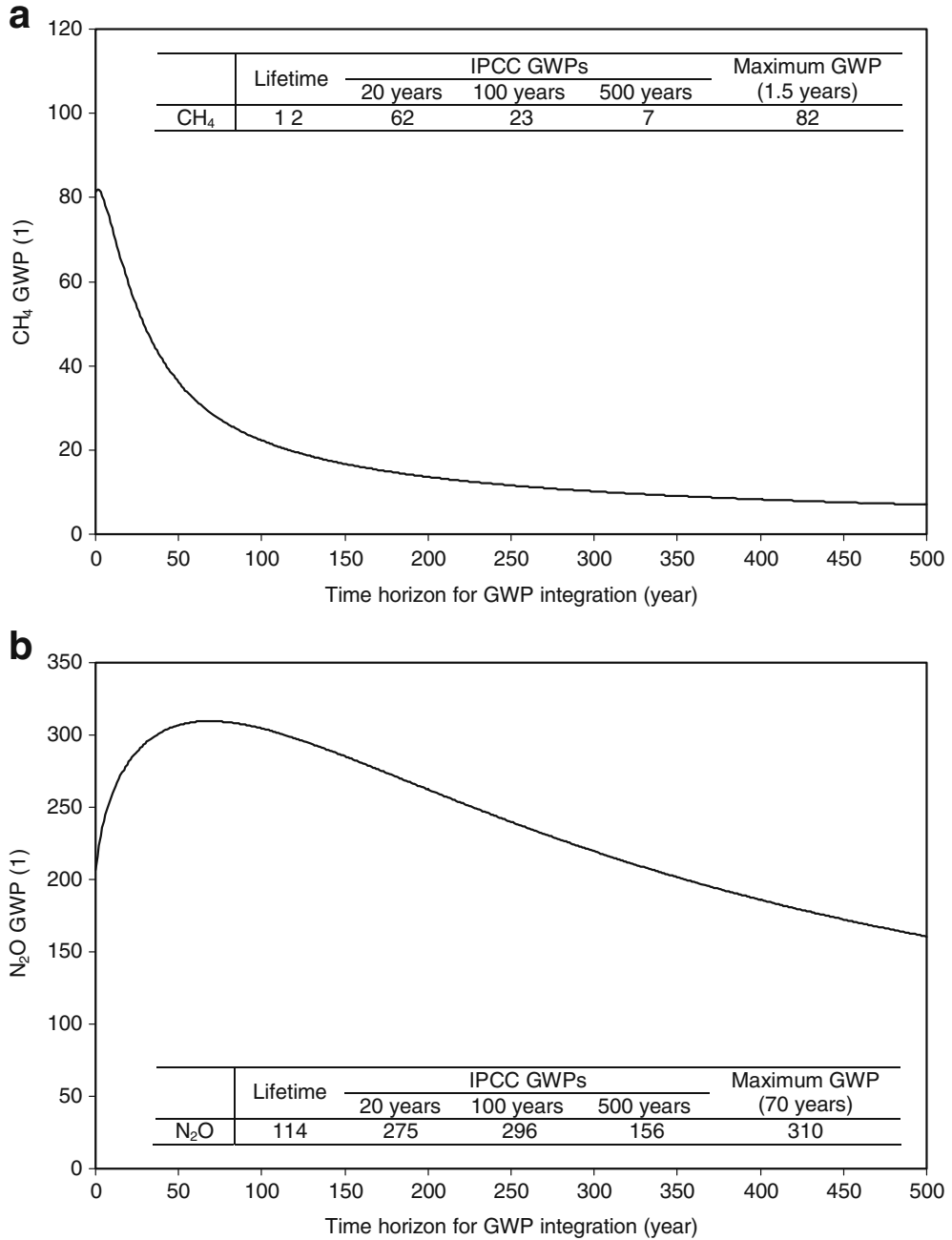

Fig. 1 a, b GWPs of $\mathrm{CH}_{4}$ and $\mathrm{N}_{2} \mathrm{O}$ with the change in time horizon. The estimates of the lifetimes and IPCC GWPs are taken from Table 6.7 of IPCC (2001). The GWP curves are calculated based on Table 1

alternatives to GWPs have been proposed (Fuglestvedt et al. 2003; Shine et al. 2005). However, no general consensus has been reached yet among researchers as to which metrics should replace the GWPs in spite of the urgent need for the post-Kyoto regime.

There are natural science-oriented and economics-oriented interpretations to GWPs (Fuglestvedt et al. 2003). Although theoretically under idealized conditions the two coincide (O’Neill 2003), in practice different evaluation methodologies result in different conclusions. From a natural science perspective, GWPs are an instrument designed to compare the relative effects on climate of various GHGs (Wigley 1998; O'Neill 2000; Smith and Wigley 2000; Smith 2003; Shine et al. 2005) while, from 
Table 1 Information used for GWP calculations

\begin{tabular}{lllll}
\hline $\begin{array}{l}\text { Names } \\
\text { of GHGs }\end{array}$ & $\begin{array}{l}\text { Molecular } \\
\text { weights }\end{array}$ & $\begin{array}{l}\text { Conversion units } \\
(\mathrm{kg} / \mathrm{ppm} \text { or } \mathrm{ppb})^{\mathrm{a}}\end{array}$ & $\begin{array}{l}\text { Lifetimes } \\
(\text { year })\end{array}$ & $\begin{array}{l}\text { Radiative efficiencies } \\
\left(\mathrm{W} / \mathrm{m}^{2} / \mathrm{ppm} \mathrm{or} \mathrm{ppb}\right)^{\mathrm{a}}\end{array}$ \\
\hline $\mathrm{CO}_{2}$ & 44 & $0.471 \times 10^{12}$ & $(150)$ & 0.01548 \\
$\mathrm{CH}_{4}$ & 16 & $2.75 \times 10^{9}$ & 12 & 0.00037 \\
$\mathrm{~N}_{2} \mathrm{O}$ & 44 & $4.80 \times 10^{9}$ & 114 & 0.0031 \\
\hline
\end{tabular}

The estimates of the lifetimes and radiative efficiencies are taken from Table 6.7 of IPCC (2001). The $\mathrm{CO}_{2}$ lifetime is merely nominal; the complex removal processes of $\mathrm{CO}_{2}$ from the atmosphere cannot be represented by a single lifetime. In the GWP calculations, the $\mathrm{CO}_{2}$ uptake is described by the impulse response function $R(T)$ (equation 10-6 of WMO 1999) as follows: $R(T)=$ $\frac{279400+72240 T+730.4 T^{2}}{279400+107000 T+3367 T^{2}+T^{3}}$, where $T$ denotes the time in years. The estimates of the conversion units are taken from Table 2 of Fuglestvedt and Berntsen (1999). They are linearly correlated with the associated molecular weights. We made an upward correction on our $\mathrm{CH}_{4} \mathrm{GWP}$ estimates by $25 \%$ as the indirect contribution to be in an agreement with the corresponding IPCC estimates

${ }^{\mathrm{a}}$ The denominator is ppm in the case of $\mathrm{CO}_{2}$ and ppb in the cases of $\mathrm{CH}_{4}$ and $\mathrm{N}_{2} \mathrm{O}$

an economic perspective, GWPs are an instrument to weight GHG emissions to achieve optimal mitigation either in a cost-effectiveness framework (Reilly et al. 1999; Manne and Richels 2001; Godal and Fuglestvedt 2002; Johansson et al. 2006) or a cost-benefit framework (Eckaus 1992; Reilly and Richards 1993; Schmalensee 1993; Fankhauser 1995; Kandlikar 1996; Tol 1999). Our study takes the natural science approach without exploring economic implications.

Here we evaluate GWPs as a proxy for the historical surface air temperature. Our study is the first to apply GWPs to historical data. GWPs by concept aim to be applied to current scenarios and have been tested only within the context of modeled futures (Fuglestvedt et al. 2000). However, it is worth investigating the performance of GWPs for the one available "real" scenario-namely, past history. Such a test may help improve our understanding of how well GWPs work and under what circumstances.

This test leads us to propose a new metric, TEMperature Proxy index (TEMP) which is designed to give a best fit to the historical temperature change, and we compare its behavior to that of GWPs.

A factor hampering the application of GWPs or other indices to historical data is the mismatch among the estimates of the GHG emissions, their concentrations, and the surface air temperature when the associated dynamic relationships are considered. This problem can be solved by adopting the inversion results for the Aggregated Carbon Cycle, Atmospheric Chemistry, and Climate Model (ACC2) (Tanaka et al. 2007) that provide a best estimate for the historical Earth system evolution since 1750 by considering the associated uncertainties. In fact, it is the crucial novel aspect of the ACC2 methodology to perform an inversion for the interactive carbon cycle, atmospheric chemistry, and climate system albeit at a global-and-annual-mean level. Currently inversions for more complex Earth system models are not operational because of the prohibitively expensive computation requirements.

The next section summarizes the ACC2 model and its inversion to be used as a basis for the GWP evaluations. In Section 3, we evaluate the IPCC GWPs for $\mathrm{CH}_{4}$ and $\mathrm{N}_{2} \mathrm{O}$ with historical temperature. In Section 4, we propose TEMP and evaluate it relative to GWPs. To better understand the evaluation results, the influences of the 
key assumptions in the IPCC GWP calculations are investigated in Section 5. The conclusions are summarized in Section 6.

\section{Model and its inversion}

\subsection{The model ACC2}

ACC2 is developed for first-order understanding of the interactions in the Earth system processes and uncertainties on a global-and-annual-mean basis. ACC2 calculates the concentrations of various GHGs, their radiative forcings, and the surface air temperature as a consequence of the emissions of GHGs and relevant agents. ACC2 version 3.1 (Tanaka 2008) is used in this study. ${ }^{2}$ The origins of ACC2 are traced back to the Nonlinear Impulse-response representation of the coupled Carbon cycleClimate System (NICCS) (Hooss 2001; Hooss et al. 2001) and the ICLIPS Climate Model (ICM) (Bruckner et al. 2003).

The functional relationships and physical and biogeochemical constants in ACC2 (Tanaka et al. 2007, Tables 2.1 and 2.2) are mostly consistent with IPCC (2001), WMO (2003), IPCC (2005), and other recent literature. No major updates are necessary according to IPCC (2007). Ocean and land $\mathrm{CO}_{2}$ uptake are each represented by a four-reservoir box model tuned to the respective impulse response functions (Maier-Reimer and Hasselmann 1987; Hooss 2001; Joos et al. 1996). Saturation in the ocean $\mathrm{CO}_{2}$ uptake with rising $\mathrm{CO}_{2}$ concentration is modelled by calculating dynamically the thermodynamic equilibria of the marine carbonate species $\left(\mathrm{CO}_{2}(a q)\right.$, $\mathrm{HCO}_{3}^{-}$, and $\mathrm{CO}_{3}^{2-}$ ). The temperature feedback to ocean $\mathrm{CO}_{2}$ uptake is provided with the equilibrium constants for marine carbonate species that are given as functions of the seawater temperature (Millero 1995; Millero et al. 2006). The $\mathrm{CO}_{2}$ fertilization of the terrestrial biosphere is parameterized by the beta factor (Gifford 1980; Friedlingstein et al. 1995), which logarithmically scales the preindustrial Net Primary Production (NPP) with the fractional increase in the atmospheric $\mathrm{CO}_{2}$ concentration. The temperature feedback to the land $\mathrm{CO}_{2}$ uptake is modeled with a Q10 parameter, which indicates how much the rate of terrestrial respiration increases with a temperature increase of $10^{\circ} \mathrm{C}$. ACC2 incorporates the parameterizations of atmospheric chemistry processes involving direct radiative forcing agents $\left(\mathrm{CO}_{2}\right.$, $\mathrm{CH}_{4}, \mathrm{~N}_{2} \mathrm{O}, \mathrm{SF}_{6}, 29$ species of halocarbons, tropospheric and stratospheric $\mathrm{O}_{3}$, and stratospheric water vapor) and indirect radiative forcing agents $\left(\mathrm{OH}, \mathrm{NO}_{x}, \mathrm{CO}\right.$, and VOC) (Joos et al. 2001), including the feedbacks of the $\mathrm{CH}_{4}$ and $\mathrm{N}_{2} \mathrm{O}$ concentrations to their lifetimes. The radiative forcings of the individual agents are calculated by the respective parameterizations. The saturations and overlaps of the $\mathrm{CH}_{4}$ and $\mathrm{N}_{2} \mathrm{O}$ absorption bands change with the $\mathrm{CH}_{4}$ and $\mathrm{N}_{2} \mathrm{O}$ concentrations, affecting the $\mathrm{CH}_{4}$ and $\mathrm{N}_{2} \mathrm{O}$ radiative forcing. The radiative forcings due to various aerosols are reduced to the following three types: the direct effect of sulfate aerosols, the direct effect of carbonaceous aerosols (black carbon and organic carbon), and the indirect effect of all aerosols (involving cloud processes). The total radiative forcing is used

\footnotetext{
${ }^{2}$ ACC2 version 3.1 (Tanaka 2008) differs from ACC2 version 3.0 (Tanaka et al. 2007) in their treatments of Q10. ACC2 version 3.1 assumes a constant Q10 value whereas ACC2 version 3.0 adopts the temperature dependency of the Q10 value (Tjoelker et al. 2001). Changes in the inversion results are not significant.
} 
to calculate the surface air temperature by the Diffusion Ocean Energy balance CLIMate model (DOECLIM) (Kriegler 2005), a land-ocean energy balance model.

\subsection{Inversion for ACC2}

In the inverse estimation for ACC2, various geophysical observational databases and functional relationships of the Earth system processes including the associated uncertainties are synthesized based on probabilistic inverse estimation theory (Tarantola 2005). Parameters in the inverse calculation include annual $\mathrm{CO}_{2}, \mathrm{CH}_{4}$, and $\mathrm{N}_{2} \mathrm{O}$ emissions, beta factor, $\mathrm{CH}_{4}$ and $\mathrm{N}_{2} \mathrm{O}$ lifetimes, climate sensitivity, and more (Tanaka et al. 2007, Table 3.2). Data in the inverse calculation are annual time series of the atmospheric $\mathrm{CO}_{2}, \mathrm{CH}_{4}$, and $\mathrm{N}_{2} \mathrm{O}$ concentrations, the ocean and land $\mathrm{CO}_{2}$ uptake, and the surface air temperature (Tanaka et al. 2007, Table 3.1). The GHG forcing and the aerosol forcing are based on model calculation, and the volcanic forcing (Ammann et al. 2003) and the solar forcing (Balmacela et al. 2007) are prescribed to the model. The types of radiative forcings that are not explicitly represented in

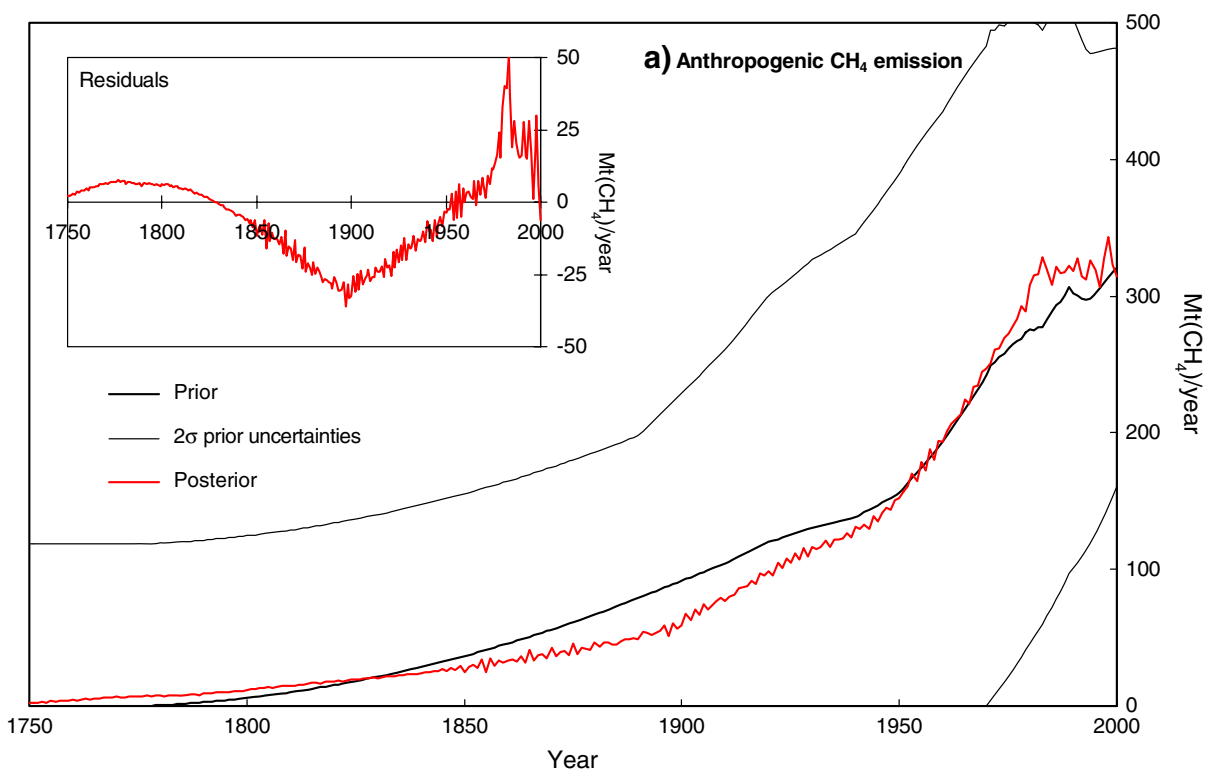

Fig. 2 a-e ACC2 inverse calculation results. The posterior estimates of the parameters and data (red lines) are shown in comparison with the respective prior estimates and measurements (black thick lines) including their $2 \sigma$ prior and measurement uncertainty ranges (black thin lines). The prior for the $\mathrm{CH}_{4}$ and $\mathrm{N}_{2} \mathrm{O}$ emissions are based on van Aardenne et al. (2001). Data for the $\mathrm{CH}_{4}$ and $\mathrm{N}_{2} \mathrm{O}$ concentrations are based on Etheridge et al. (1998), Jacqueline Flückiger (personal communication), Hansen and Sato (2004), and Masarie et al. (2001, Table 1). Data for the surface air temperature are the compilation of Jones et al. (1998, 2006), and Mann and Jones (2003). The large spikes in the prior parameter and data uncertainties are due to the adjustments for large volcanic eruptions (Tanaka et al. 2007, Section 3.5.2). The residuals of the posterior estimates from their corresponding prior estimates (red lines in inserts) are separately shown in inserts with their $2 \sigma$ prior and measurement uncertainty ranges (black lines in inserts). The full inversion results are shown in Tanaka et al. (2007, Section 4) 

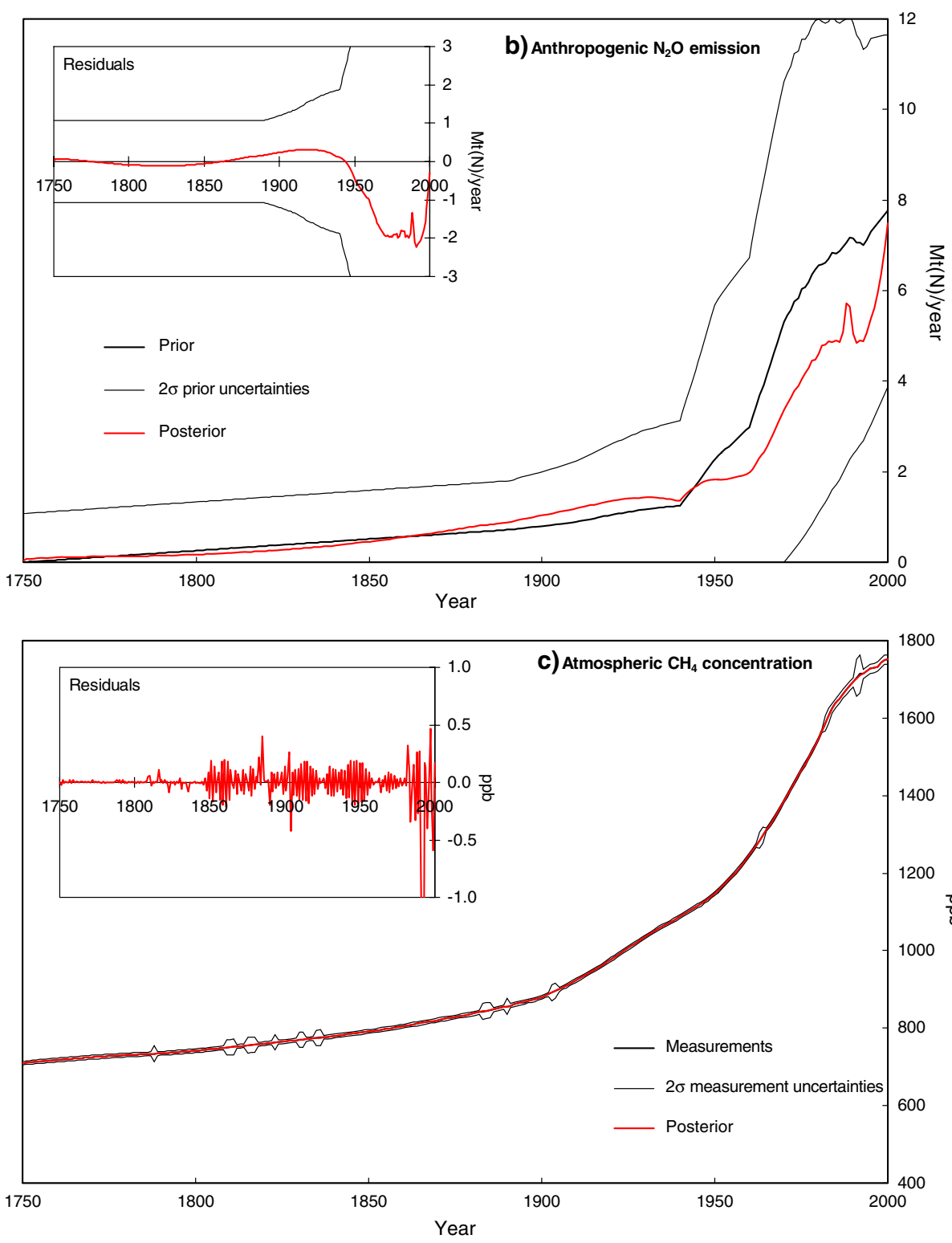

Fig. 2 (continued)

ACC2 (e.g., albedo forcing) are lumped together and represented as the "missing forcing." The missing forcing has a degree of freedom in every year and is treated as parameters. The uncertainties in the GHGs, aerosol, volcanic, and solar forcings are also contained in the missing forcing term. Furthermore, variability in temperature records is partly accounted for by missing forcing. More discussion on missing forcing is found in Tanaka et al. (2008). Gaussian distributions are assumed for all the prior parameter and measurement uncertainties. Our inversion setup produces particular 

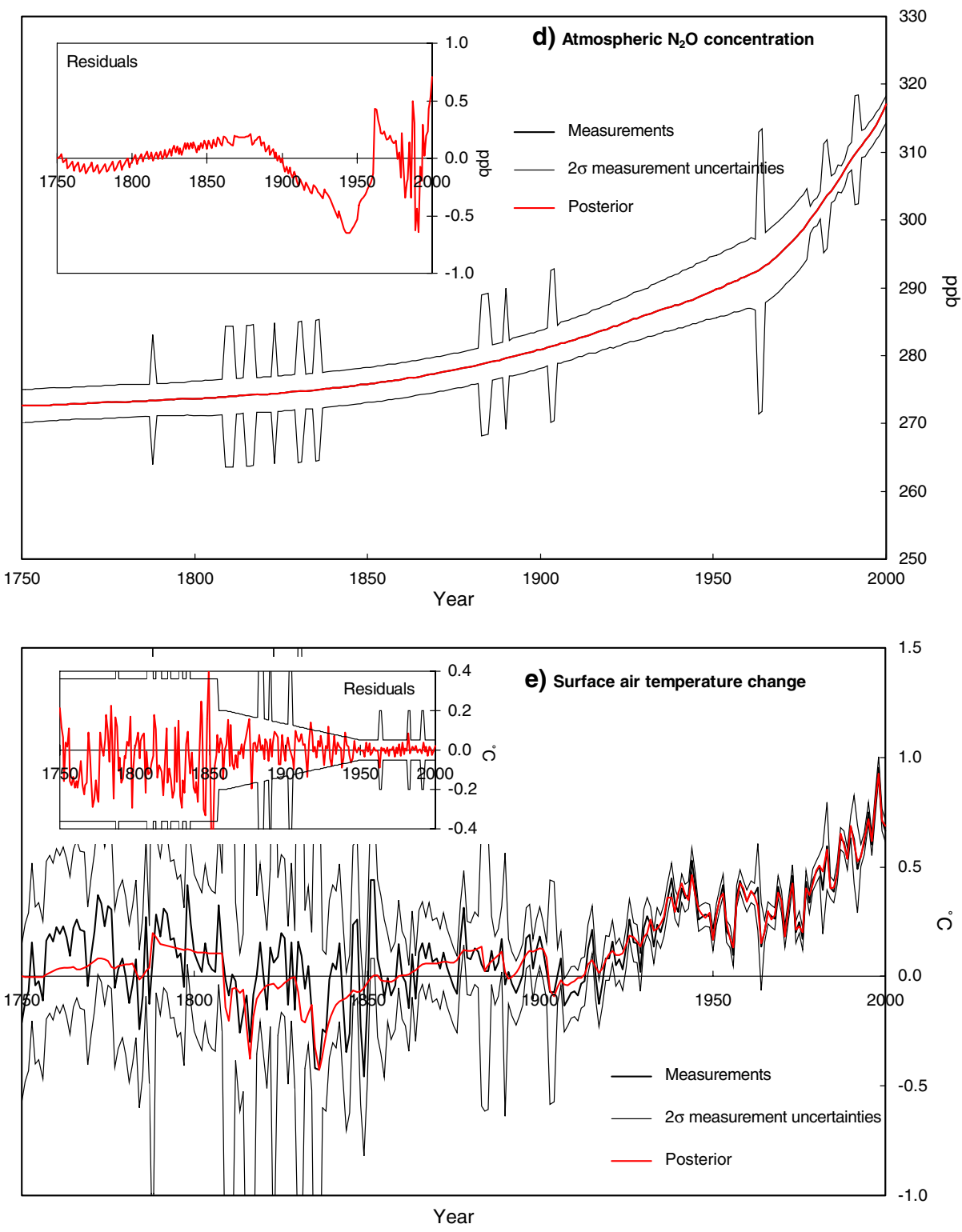

Fig. 2 (continued)

posterior estimates of the parameters and the data corresponding to the minimum of the cost function and does not provide associated posterior probability distributions. Numerically, we optimize the parameter values to minimize the following cost function:

$$
S(\mathbf{m})=\frac{1}{2}\left(\sum_{i=1}^{a}\left(\frac{g_{i}(\mathbf{m})-d_{m e s, i}}{\sigma_{d, i}}\right)^{2}+\sum_{j=1}^{b}\left(\frac{m_{j}-m_{\text {prior }, j}}{\sigma_{m, j}}\right)^{2}\right)
$$


$g_{i}(\mathbf{m})$ is the forward model projection for data $i$ based on a set of parameter $\mathbf{m}$. $a$ and $b$ are the total numbers of data and parameters, respectively. $d_{\text {mes, } i}$ and $m_{\text {prior, } j}$ denote measurement $i$ and prior estimate of parameter $j$, respectively. $\sigma_{d, i}$ and $\sigma_{m, j}$ are one-sigma uncertainty ranges for measurement $i$ and for prior estimate of parameter $j$, respectively. Note that all of the errors in the parameters and the data are treated independently. The optimization is performed using CONOPT3 in GAMS.

The inverse calculation results are shown in Fig. 2a-e. The posterior estimates of the $\mathrm{CH}_{4}$ and $\mathrm{N}_{2} \mathrm{O}$ concentrations turned out to be almost identical to the corresponding measurements because of the adjustments in the $\mathrm{CH}_{4}$ and $\mathrm{N}_{2} \mathrm{O}$ emissions that have much larger prior uncertainties. The full inversion results are shown and discussed in Tanaka et al. (2007, Section 4). All in all, the ACC2 inversion generated a best estimate of the historical Earth system evolution from the year 1750 to 2000, which we use as the basis for the GWP evaluation in the following sections.

\section{Evaluation of GWPs}

We take the Earth system evolution obtained from the ACC2 inversion as our 'baseline.' We replace the baseline anthropogenic $\mathrm{CH}_{4}$ and $\mathrm{N}_{2} \mathrm{O}$ emissions (separately) with their equivalent $\mathrm{CO}_{2}$ emissions using GWPs as conversion coefficients. Then, by fixing all the other parameter values at the respective baseline levels, we calculate the surface air temperature and compare with the baseline temperature. We use temperature to compare outcomes, although results are similar for radiative forcing, a measure closer to the GWP definition, which can be inferred from the results in Appendix 1.1. The GWP-based emission conversions are applied beginning in 1890, the earliest year in which estimates of the anthropogenic $\mathrm{CH}_{4}$ and $\mathrm{N}_{2} \mathrm{O}$ emissions are available (van Aardenne et al. 2001). Even if we apply the GHG conversion from a later start year, the overall results hold (as can be inferred from Appendix 1.2). We deal with only $\mathrm{CH}_{4}$ and $\mathrm{N}_{2} \mathrm{O}$ in this paper as $\mathrm{CH}_{4}$ and $\mathrm{N}_{2} \mathrm{O}$ are distinct GHGs in terms of their lifetimes and feedbacks, from which the essence of this paper can be derived. Testing for HFCs, which currently account for a significant share of the Clean Development Mechanism (CDM) market, would be an extension of our study.

Figure 3a shows the temperature projections when the $\mathrm{CH}_{4}$ emissions are converted to equivalent $\mathrm{CO}_{2}$ emissions based on the IPCC GWPs with the 20-, 100-, and 500-year time horizons. In all three cases, the temperature projection is not well reproduced and the deviations are up to $0.30^{\circ} \mathrm{C}$ in the year 2000 compared to a total change over the period of about $0.7^{\circ} \mathrm{C}$. In particular, the temperature projection using the 100 -year $\mathrm{CH}_{4} \mathrm{GWP}$ is lower than the baseline temperature projection by $0.13^{\circ} \mathrm{C}$, suggesting that a GWP with a shorter time horizon would perform better. This is qualitatively in line with the results of Smith and Wigley (2000), who demonstrate that the 100-year time horizon is too long for $\mathrm{CH}_{4} \mathrm{GWP}$ in a more idealized setting. Also in the case of $\mathrm{N}_{2} \mathrm{O}$ (Fig. 3b), the three IPCC GWPs do not reproduce the historical temperature, leaving a deviation of up to $0.05^{\circ} \mathrm{C}$ in the year 2000. The temperature projection using the 100-year $\mathrm{N}_{2} \mathrm{O}$ GWP underestimates the baseline by $0.012^{\circ} \mathrm{C}$. The deviations are larger in the $\mathrm{CH}_{4}$ experiment than in the $\mathrm{N}_{2} \mathrm{O}$ experiment because the $\mathrm{CH}_{4}$ radiative forcing is larger and also because the $\mathrm{CH}_{4} \mathrm{GWP}$ is more sensitive to the time horizon due to its short lifetime (Fig. 1a, b). 


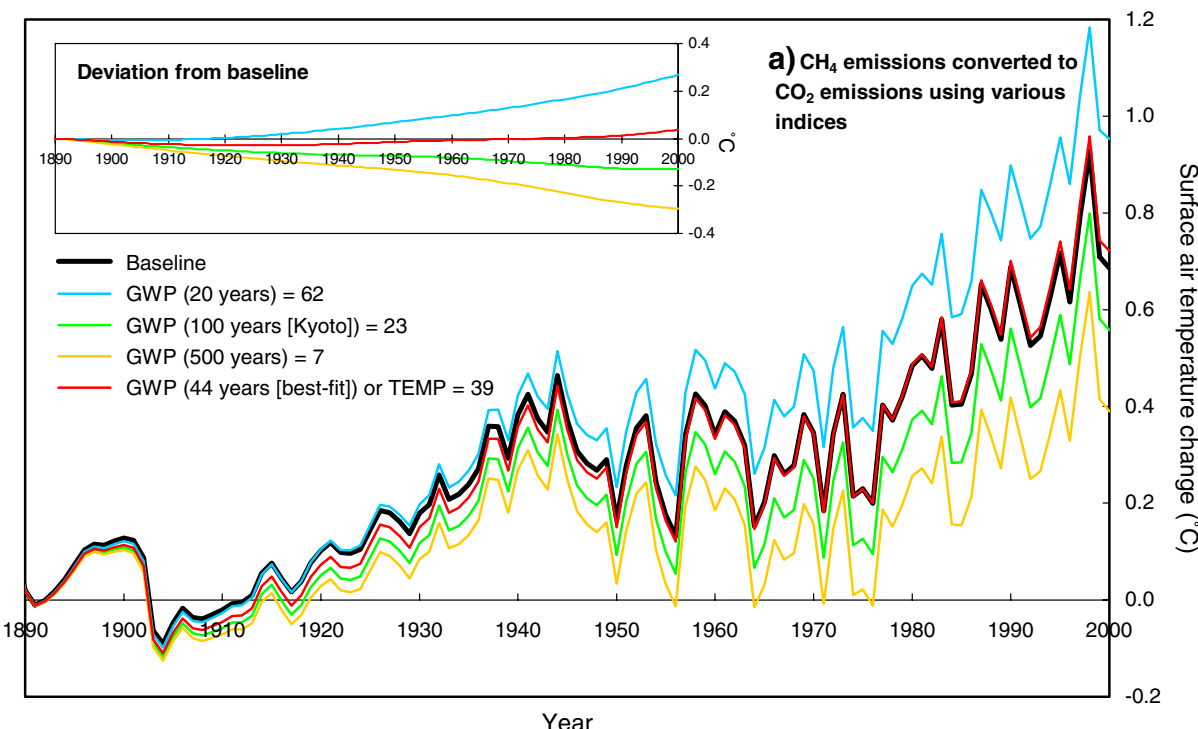

Year

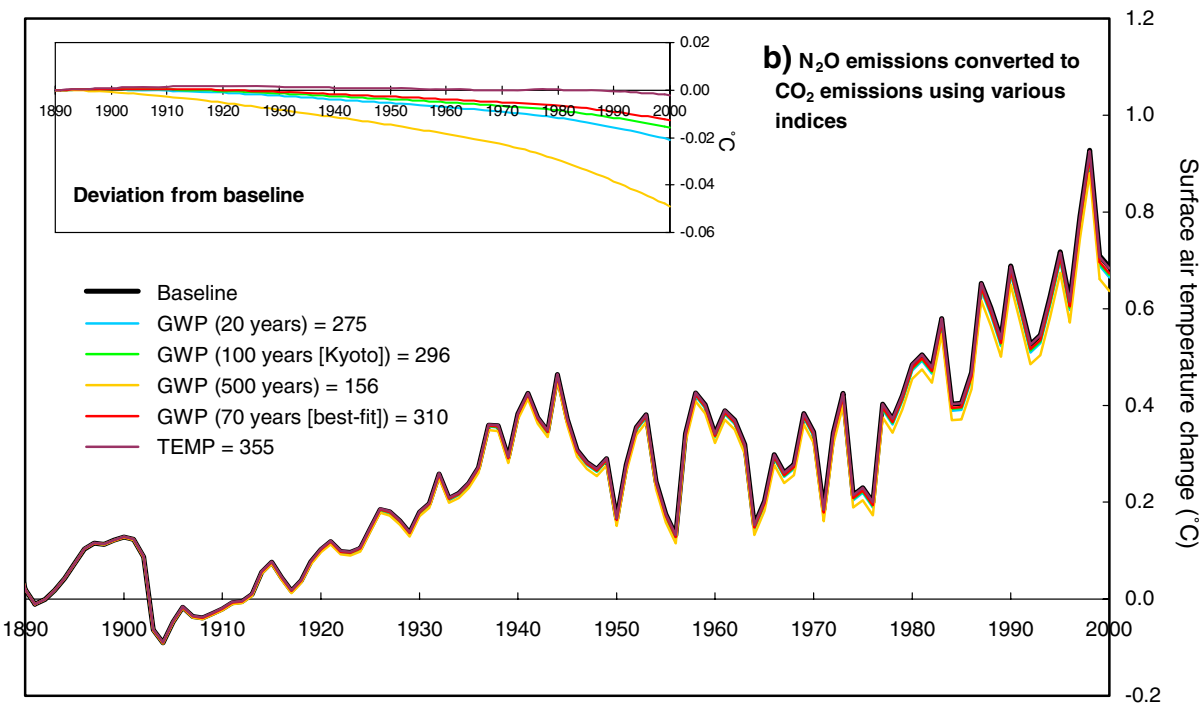

Year

Fig. 3 a, b Temperature projections with $\mathrm{CH}_{4}$ or $\mathrm{N}_{2} \mathrm{O}$ emissions converted using GWPs and TEMPs. The conversions are applied from the year 1890 onward. Baselines are the posterior estimates obtained from the ACC2 inverse calculation. The temperature projection using the $\mathrm{CH}_{4}$ TEMP is identical with the projection using the best-fit $\mathrm{CH}_{4} \mathrm{GWP}$

Although the absolute temperature deviations for the $\mathrm{N}_{2} \mathrm{O}$ GWP are small, they are important because $\mathrm{N}_{2} \mathrm{O}$ is one of the dominant non- $\mathrm{CO}_{2}$ GHGs with respect to radiative forcing. The results of the IPCC GWP evaluations suggest that in the context of the historical scenario, non- $\mathrm{CO}_{2}$ gases should be valued more than they currently are by the 100-year GWPs. 
Could it be that the baseline temperature projections are not reproduced well with GWPs because we use three arbitrary time horizons? To find out, we solved for the time horizon for $\mathrm{CH}_{4}$ and $\mathrm{N}_{2} \mathrm{O}$ GWPs that best reproduce the baseline temperature projection (that is, the sum of the squared distances between the GWPbased temperature and the baseline temperature during the period 1890-2000 is minimized; Fig. 3a, b). Note that this is different from testing the effect of using a time dependent GWP (e.g., Wigley 1998). Here, at each point in time, we find the single, constant GWP value that would perform best over the historical period. The time horizons for $\mathrm{CH}_{4}$ and $\mathrm{N}_{2} \mathrm{O}$ GWPs that yield the best fits are approximately 44 and 70 years, respectively. However, while in the $\mathrm{CH}_{4}$ case the temperature projection using the best-fit GWP appears to be a good fit to the baseline temperature projection (insert for Fig. 3a), in the $\mathrm{N}_{2} \mathrm{O}$ case the temperature projection using the best-fit GWP still lies considerably below the baseline projection (insert for Fig. 3b).

These results, puzzling at first sight, are related to the fact that the GWP values cover only a restricted range as a function of the assumed time horizon (Fig. 1a, b). The $\mathrm{CH}_{4}$ GWP reaches its maximum with an extremely short time horizon of approximately 1.5 years and decreases thereafter due to its short lifetime. The $\mathrm{N}_{2} \mathrm{O}$ GWP is maximized with the time horizon of approximately 70 years and falls off on both sides. This occurs because of the nature of the removal timescale for $\mathrm{CO}_{2}$, which is relatively fast for several decades and then slows considerably. Thus, $\mathrm{CO}_{2}$ is removed faster than $\mathrm{N}_{2} \mathrm{O}$ at first, and then later is removed more slowly, which produces first a rising and then a falling value of $\mathrm{N}_{2} \mathrm{O}$ GWP as the time horizon lengthens. The range of values covered by the $\mathrm{N}_{2} \mathrm{O}$ GWP does not include the value that would reproduce historical temperature.

\section{TEMperature Proxy index (TEMP)}

Now we introduce new GHG exchange metrics, TEMPs. A TEMP is a non-physical quantity that provides a best fit to the baseline temperature projection when it is used to convert non- $\mathrm{CO}_{2} \mathrm{GHG}$ emissions to their $\mathrm{CO}_{2}$-equivalents. The $\mathrm{CH}_{4}$ TEMP for emissions over the 1890-2000 period is approximately 39, equal to the best-fit $\mathrm{CH}_{4}$ GWP (44-year time horizon). On the other hand, the $\mathrm{N}_{2} \mathrm{O}$ TEMP is 355 whereas the best-fit $\mathrm{N}_{2} \mathrm{O}$ GWP (70-year time horizon) is 310, equal to the maximum $\mathrm{N}_{2} \mathrm{O}$ GWP. The disparity between the $\mathrm{N}_{2} \mathrm{O}$ TEMP and the best-fit $\mathrm{N}_{2} \mathrm{O}$ GWP indicates that the range for the $\mathrm{N}_{2} \mathrm{O}$ GWP does not contain the value for the optimal temperature proxy.

The TEMP is related in spirit to the Forcing Equivalence Index (FEI) proposed by Wigley (1998) in that it is a value calculated in order to produce equal outcomes from two different mixes of emissions. The FEI is an instantaneous, time-varying index that produces identical radiative forcing pathways over time. In contrast, the TEMP is an index that remains constant over a specified time horizon, and is calculated to produce a best-fitting (although not necessarily identical) temperature pathway over time.

It is useful to investigate how the value of the TEMP depends on the period over which the fit to the temperature record is evaluated. We therefore repeat the same fitting exercise for different periods. First, we maintain a start year of 1890 while progressively changing the end year from 1891 to 2000 in 1-year steps. This 
version of the TEMP can be described as backward-looking: one looks back from a constantly updated end year to the start year to determine the best-fitting value over the period that has passed. The results (Fig. 4a) show that the backward-looking TEMP for $\mathrm{CH}_{4}$ declines with increasing length of the optimization period, consistent with behavior of the FEI for $\mathrm{CH}_{4}$ calculated by Wigley (1998) for several future scenarios. Given the short lifetime of $\mathrm{CH}_{4}$ compared to $\mathrm{CO}_{2}$, its value is highest when optimization occurs over the shortest period, and declines as the optimization period lengthens. The backward-looking TEMP value begins outside the range of
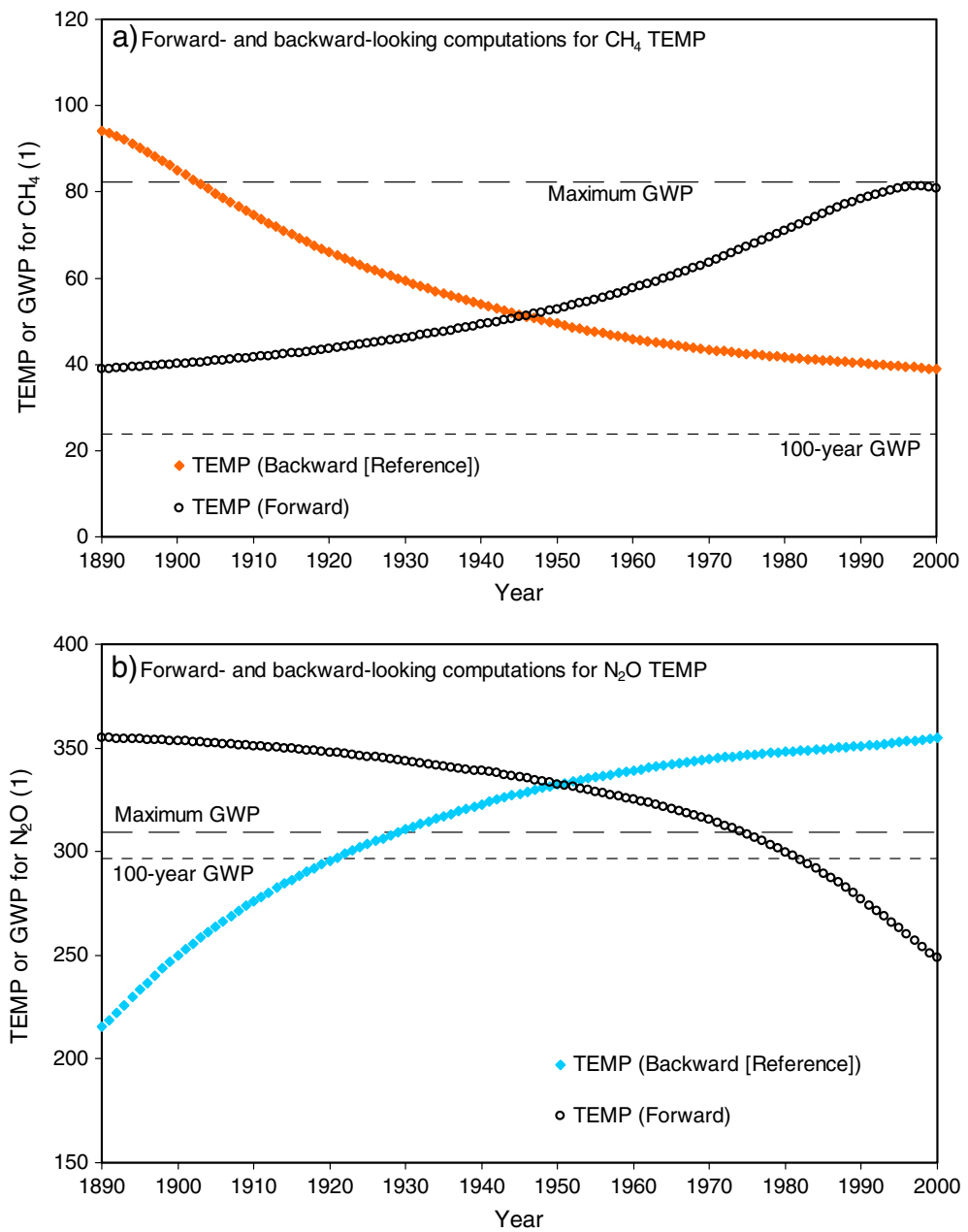

Fig. 4 a, b $\mathrm{CH}_{4}$ and $\mathrm{N}_{2} \mathrm{O}$ TEMPs calculated over different time periods. In the backward-looking calculations, TEMPs are optimized with respect to their fits to the baseline temperature between the year 1890 and the end year shifting from 1900 to 2000. In the forward-looking calculations, TEMPs are optimized between starting years ranging from 1890 to 2000 and the year 2000. The backwardlooking calculation results serve as a reference for the rest of our analysis 
possible GWP values, and then falls within it for fitting periods that are greater than 13 years.

In contrast, the results for $\mathrm{N}_{2} \mathrm{O}$ (Fig. 4b) show that the backward-looking TEMP increases with increasing length of the optimization period, and begins within the range of possible GWP values but exceeds this range for optimization periods longer than 40 years. The increasing trend is a result of the fact that, as discussed above, the removal rate of a pulse emission of $\mathrm{N}_{2} \mathrm{O}$ is slower than that of $\mathrm{CO}_{2}$ for many decades, and faster only much later when $\mathrm{CO}_{2}$ uptake slows (O'Neill et al. 1997). Thus at least initially, the $\mathrm{N}_{2} \mathrm{O}$ TEMP value behaves as it would for a gas with a lifetime longer than that of $\mathrm{CO}_{2}$ : it rises as the optimization period lengthens. As the optimization period grows longer yet, the emissions being traded off slowly shift from recent emissions (for which $\mathrm{N}_{2} \mathrm{O}$ removal is slower than $\mathrm{CO}_{2}$ ) to a growing fraction of older emissions (for which $\mathrm{N}_{2} \mathrm{O}$ removal is faster than $\mathrm{CO}_{2}$ ). For the particular emissions pathways over the historical period, this leads to a $\mathrm{N}_{2} \mathrm{O}$ TEMP that grows more and more slowly over time, but does not decline.

While these results provide insight into the effect of the optimization period on the value of the TEMP, they are less useful for insight into how a TEMP value might be applied within a forward-looking policy setting. For example, from the perspective of the year 1890, an index aimed at equating the effect of different gases over the period 1890-2000 would want to begin with the value that was optimal over that entire period. In the next year, the relevant TEMP would be the optimal value over the period 1891-2000, and so on through time, at each point looking forward from an updated start year to a common end year. This computation method is similar to the formulation of the Global Temperature change Potential (GTP) (Shine et al. 2005, 2007), a ratio of temperature change in a target year. But the notable difference is that GTP is an endpoint metric whereas GWP and TEMP are integrative measures.

Figure $4 \mathrm{a}$, b show these forward-looking TEMP values calculated by maintaining the end year of the optimization period at 2000, and progressively changing the start year from 1890-2000 in 1-year steps. In contrast to the backward-looking TEMP, the forward-looking TEMP for $\mathrm{CH}_{4}$ rises over time, rather than falls. The reasoning is the same: with a short lifetime, $\mathrm{CH}_{4}$ reductions early in the period, when the optimization period is long, are not valuable relative to reductions later in the period, when the optimization period is short. This rising value of $\mathrm{CH}_{4}$ reductions is opposite to the trend in the FEI (Wigley 1998), but similar to that found by Manne and Richels (2001) in their calculation of the economic value of reductions of different gases using price ratios and by Shine et al. $(2005,2007)$ in their calculation of GTPs. The trends in the forward-looking TEMP, price ratios, and GTPs share a common cause: as the overall temperature scenario approaches a temperature target or the end of the optimization period, the relative contribution of short-lived gases increases and is reflected in the rising index.

The results for $\mathrm{N}_{2} \mathrm{O}$ are also the opposite of the backward-looking calculation, showing a declining (rather than rising) TEMP value over time. $\mathrm{N}_{2} \mathrm{O}$ reductions are more valuable early on because of the expectation that $\mathrm{N}_{2} \mathrm{O}$ emissions over the full optimization period will on balance be more slowly removed than $\mathrm{CO}_{2}$. Thus the earlier the optimization period begins, the more valuable reductions in $\mathrm{N}_{2} \mathrm{O}$ will be. In fact, the forward-looking TEMP for $\mathrm{N}_{2} \mathrm{O}$ lies outside the range of possible GWP values for nearly the entire period. In the next section, we explore the reasons for this mismatch. 


\section{Assumptions in the IPCC GWP calculations}

The IPCC GWP calculations use a simplified approach to representing carbon cycle processes, $\mathrm{CH}_{4}$ and $\mathrm{N}_{2} \mathrm{O}$ atmospheric chemistry, and associated concentrationforcing relationships. As the different process representations lead to different index values, we compute TEMPs under the assumptions used in the IPCC GWP calculations. This exercise is useful to gain an insight into the disparity between the $\mathrm{N}_{2} \mathrm{O}$ TEMP and GWP ranges. Namely, we assume a low $\mathrm{CO}_{2}$ fertilization (beta = 0.287) as in the Bern Carbon Cycle Model (Joos et al. 1996) adopted for the IPCC GWP calculations (IPCC 2001, p.386), the $\mathrm{CH}_{4}$ lifetime of 12 years (IPCC 2001, Table 6.7) equivalent to the $\mathrm{CH}_{4}$ lifetime with respect to $\mathrm{OH}$ depletion of 14.5 years (Appendix 2.2), the $\mathrm{N}_{2} \mathrm{O}$ lifetime of 114 years (IPCC 2001, Table 6.7),
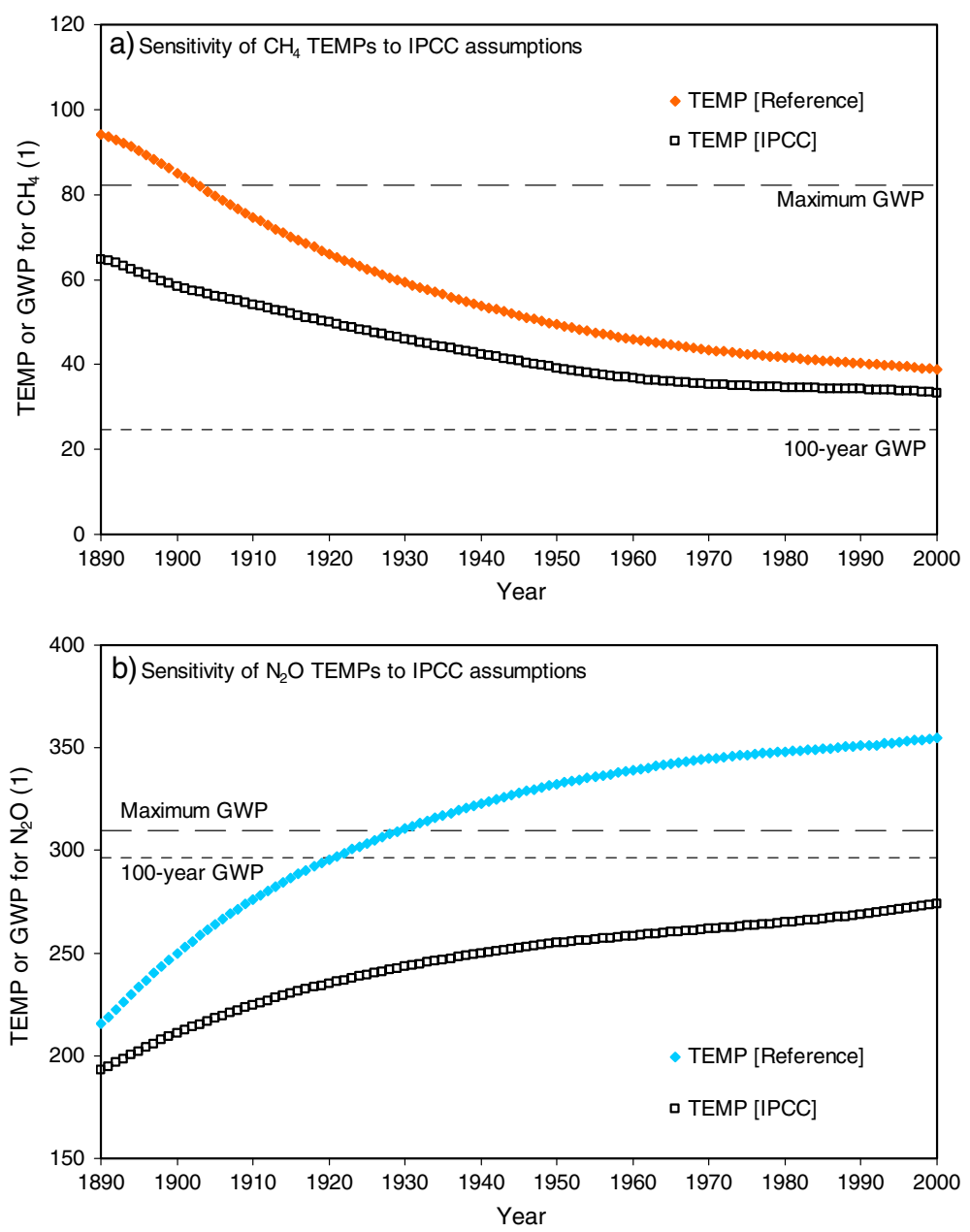

Fig. 5 a, b Updating $\mathrm{CH}_{4}$ and $\mathrm{N}_{2} \mathrm{O}$ TEMPs under the assumptions used for IPCC GWP calculations. Backward-looking TEMPs are calculated for every year from 1890 to 2000 
linear marine carbonate chemistry by fixing the Revelle factor at the present level (Revelle and Munk 1977; Mackenzie and Lerman 2006, p.265), no $\mathrm{CH}_{4}$ and $\mathrm{N}_{2} \mathrm{O}$ concentration feedbacks to their own lifetimes, linear $\mathrm{CH}_{4}$ and $\mathrm{N}_{2} \mathrm{O}$ concentrationforcing relationships (no change in the saturations and overlaps of the $\mathrm{CH}_{4}$ and $\mathrm{N}_{2} \mathrm{O}$ absorption bands), and no climate-carbon cycle feedback by keeping the temperature seen by the carbon cycle at the preindustrial level. Note that the other parameters not mentioned above are adjusted in the inverse calculation according to the change in assumptions for IPCC GWP calculations.

The TEMP calculation results under the IPCC assumptions are compared with the reference results in Fig. 5a, b. With the assumptions used in the IPCC GWP calculations, both the $\mathrm{CH}_{4}$ and $\mathrm{N}_{2} \mathrm{O}$ TEMPs stay below their respective maximum GWPs. A sensitivity analysis with respect to each of the assumptions (Appendix 2.1 to 2.3) shows that the ones having the largest effect are the low beta factor and the linearization of the $\mathrm{CH}_{4}$ and $\mathrm{N}_{2} \mathrm{O}$ concentration-forcing relationships. Unlike our high beta factor $(=0.59)$, the low beta factor assumed in the IPCC GWP calculations is not supported by most of the recent process-based terrestrial biosphere models (Friedlingstein et al. 2006). The linear $\mathrm{CH}_{4}$ and $\mathrm{N}_{2} \mathrm{O}$ concentration-forcing relationships assumed in the IPCC GWP calculations are an oversimplification as the background system dynamics are expected to change on the time scale of global climate policy, a well-known problem with GWPs. In the context of the Earth system history, the assumptions used in the IPCC GWP calculations would not be satisfied, indicating that the current GWPs are detached from how the Earth system has actually behaved. The mismatch between the $\mathrm{N}_{2} \mathrm{O}$ GWP range and the TEMP value is caused by the IPCC GWP calculation methodology not representing sufficient complexity in the system dynamics and also not rigorously treating uncertain parameters.

\section{Discussion and concluding remarks}

We have demonstrated that the $\mathrm{CH}_{4}$ and $\mathrm{N}_{2} \mathrm{O}$ GWPs used in the Kyoto Protocol, when applied to historical emissions, lead to an underestimation of historical temperature change. We show however that a single constant index can in principle reproduce this history well, and we introduce a new index, the TEMperature Proxy (TEMP) that is designed to do so. The TEMP for $\mathrm{CH}_{4}$ is equivalent to a GWP calculated with a 44-year time horizon, but the TEMP for $\mathrm{N}_{2} \mathrm{O}$ is not consistent with any time horizon used to calculate a GWP. We show that this discrepancy is due to the simplified earth system dynamics used to calculate GWPs, as well as parameter estimates in the models on which GWPs are based that are inconsistent with other data from the historical period.

Thus, our results add to previous work illustrating the shortcomings of the GWP concept. While it is not clear that changing to a different index for use in climate policy would have any substantial economic advantage (Godal and Fuglestvedt 2002; O'Neill 2003; Aaheim et al. 2006), debate continues over what index would have the best theoretical justification and most appealing empirical properties for use in climate policy. Recent attention has focused on price ratios, economic indices designed to be optimal within a cost effectiveness framework, and GTPs, purely physically-based approximations of price ratios. The forward-looking version of 
the TEMP that we calculate over the historical period shares qualitatively similar features with these two indices. In particular, the value of reductions of shortlived gases rises over time as a constraint, or the end of the optimization period, is approached.

Evaluating the potential for TEMPs to play a role in greenhouse gas emissions policy would require deriving them and evaluating their performance for a variety of future scenarios, and comparing them to other indices in terms of both performance and theoretical justification. Although we have not yet carried out such an analysis, we believe that TEMPs, or some variant of the concept, may hold promise as a physically-based index like the GTP. As we have noted, the key difference between the two is that GTPs reflect relative effects on temperature change at a single point in time, while TEMPs reflect integrated relative effects on temperature over an entire time period. TEMPs may be more appropriate to situations in which it is desired to follow a particular pathway of temperature change over time (including, for example, a constraint on rate of change), whereas GTPs are best suited to situations in which only the maximum temperature constraint matters, and the pathway to reaching it does not. We leave exploration of these issues to further work.

Acknowledgements This study has been initiated during the correspondence author's stay at the International Institute for Applied Systems Analysis (IIASA) as a participant of the Young Scientist Summer Program (YSSP) in 2005. This study is financially supported by European Commission (ENSEMBLES project), International Max Planck Research School on Earth System Modelling, and IIASA. We appreciate four anonymous reviewers for their critical and constructive comments.

\section{Appendix 1: GWP evaluation methodology}

We first show a further analysis of our GWP evaluation methodology in terms of the reference for TEMP computation (Appendix 1.1) and the start year for TEMP computation (Appendix 1.2).

\subsection{Reference for TEMP computation}

Here the effect of using temperature as the reference for TEMP computation is looked into. We similarly compute TEMPs by using radiative forcing as a reference (Fig. 6a, b). The results are nearly identical except for the slight delay in the standard TEMPs due to the inertia of the temperature response to a change in radiative forcing. The finding here also indicates that the GWP evaluation results would also be similar if using radiative forcing reference.

\subsection{Start year for TEMP computation}

We investigate the influence of the start year of 1890 to apply the GHG conversion by performing similar TEMP updating computations for different start years (Fig. 6c, d). The general trend of the $\mathrm{CH}_{4}$ and $\mathrm{N}_{2} \mathrm{O}$ TEMPs does not change. The problem of having the $\mathrm{N}_{2} \mathrm{O}$ TEMP above the maximum $\mathrm{N}_{2} \mathrm{O}$ GWP persists. Irrespective of the 
Fig. 6 a-d Optimizing TEMPs by different computational methods: a, b references; and c, d start years. Backward-looking TEMPs are calculated for every year from 1890 to 2000

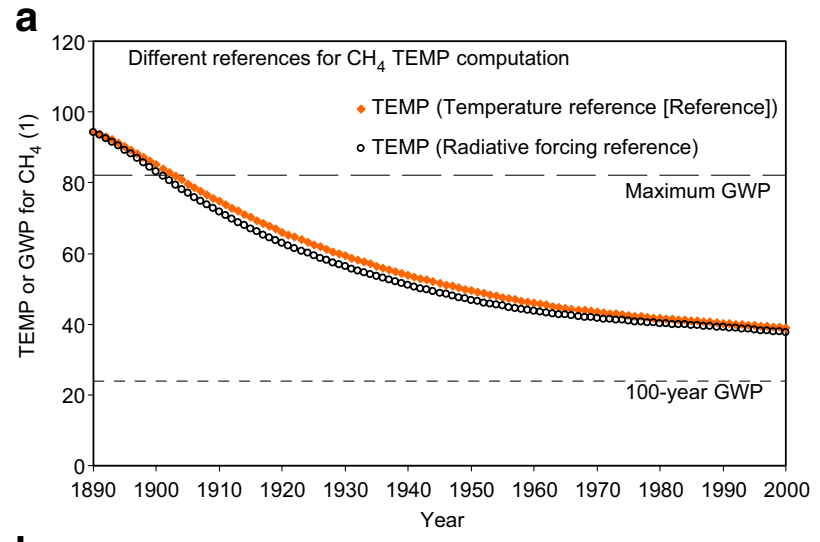

b

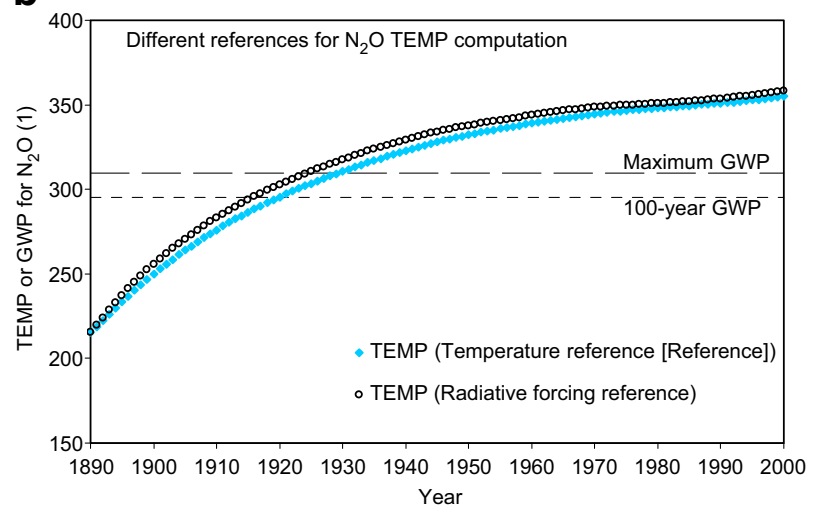

start year, it appears that the $\mathrm{CH}_{4}$ and $\mathrm{N}_{2} \mathrm{O}$ TEMPs follow similar paths and converge to certain values.

\section{Appendix 2: Individual assumptions in IPCC GWP calculations}

In Section 5, we show the effect of all the IPCC assumptions to TEMPs. Here we investigate the influences of the individual IPCC assumptions, namely, $\mathrm{CO}_{2}$ fertilization (Appendix 2.1), $\mathrm{CH}_{4}$ and $\mathrm{N}_{2} \mathrm{O}$ lifetimes (Appendix 2.2), and process simplifications (Appendix 2.3).

\section{$2.1 \mathrm{CO}_{2}$ fertilization}

The literature estimates of the beta factor substantially vary between 0.15 and 0.6 (e.g., Kohlmaier et al. 1987). We fix the beta factor at a very low level $(=0.15)$ and the IPCC level $(=0.287)$ and perform inverse calculations for the respective cases. The 
Fig. 6 (continued)
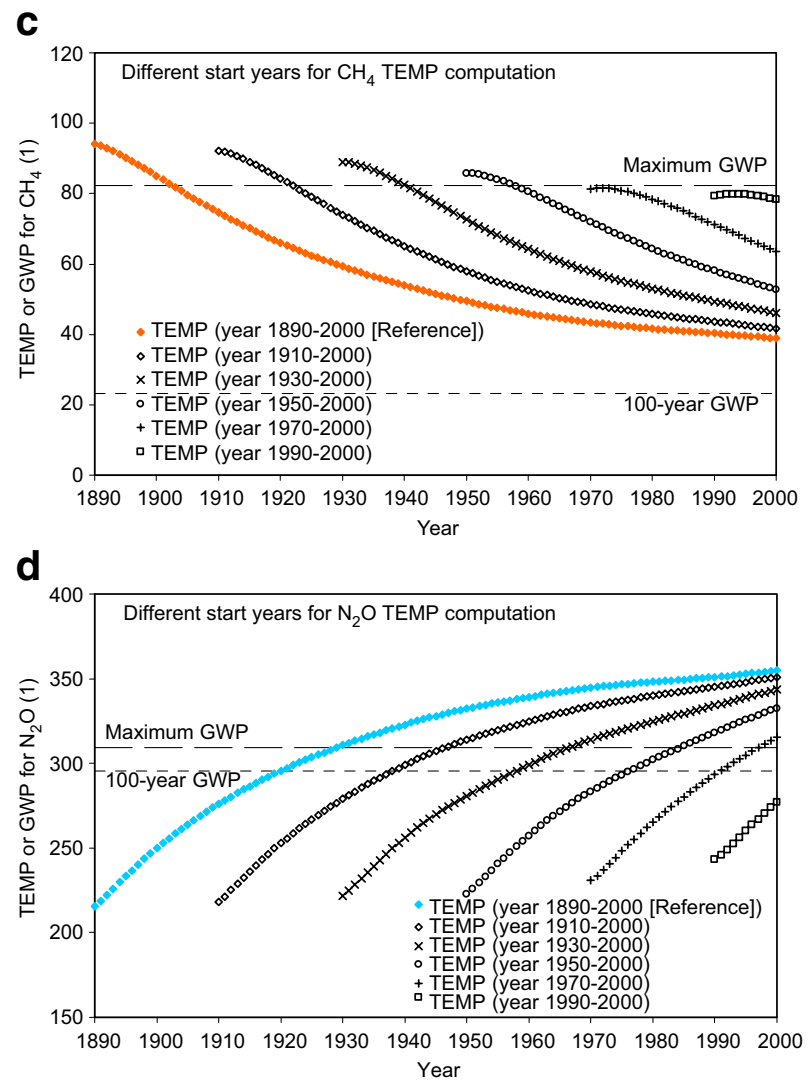

results of these inversions provide their respective best estimates of the parameters to be used for TEMP computations. It should be noted that the TEMP computations for the lower beta factors are based on different inversion results because the best estimates of all the parameters have to be re-computed to reflect the assumption on the beta factor. Figure $7 \mathrm{a}, \mathrm{b}$ show the respective TEMP updating experiments, indicating that the weaker the $\mathrm{CO}_{2}$ fertilization, the lower the TEMPs. A low $\mathrm{CO}_{2}$ fertilization means less carbon storage in the terrestrial biosphere, implying a longer $\mathrm{CO}_{2}$ lifetime in the atmosphere. As a result, the influence of the $\mathrm{CO}_{2}$ emissions to the temperature is enhanced, lowering the TEMP for $\mathrm{CH}_{4}$ and $\mathrm{N}_{2} \mathrm{O}$. When the $\mathrm{CO}_{2}$ fertilization is assumed to be at the level for the IPCC GWP calculations, the TEMP projection is substantially lowered. In the case of very low $\mathrm{CO}_{2}$ fertilization, the $\mathrm{N}_{2} \mathrm{O}$ TEMP stays below the maximum $\mathrm{N}_{2} \mathrm{O}$ GWP throughout the updating exercise. Our inverse calculation indicates that assuming the very low $\mathrm{CO}_{2}$ fertilization of 0.15 is not realistic because the $\mathrm{CO}_{2}$ emissions have to be unacceptably low to counteract the atmospheric $\mathrm{CO}_{2}$ build-up owing to the very low $\mathrm{CO}_{2}$ fertilization. The results of the sensitivity analysis here suggest that the low beta factor assumed in the IPCC GWP in part explains why the $\mathrm{N}_{2} \mathrm{O}$ GWP does not function as a historical temperature proxy. 
Fig. 7 a-f Sensitivities of TEMPs to the different system dynamics and uncertain parameter estimates: a, b beta factor; c, d $\mathrm{CH}_{4}$ lifetime with respect to $\mathrm{OH}$ depletion and $\mathrm{N}_{2} \mathrm{O}$ lifetime; and e, f process simplifications. Backward-looking TEMPs are calculated for every year from 1890 to 2000
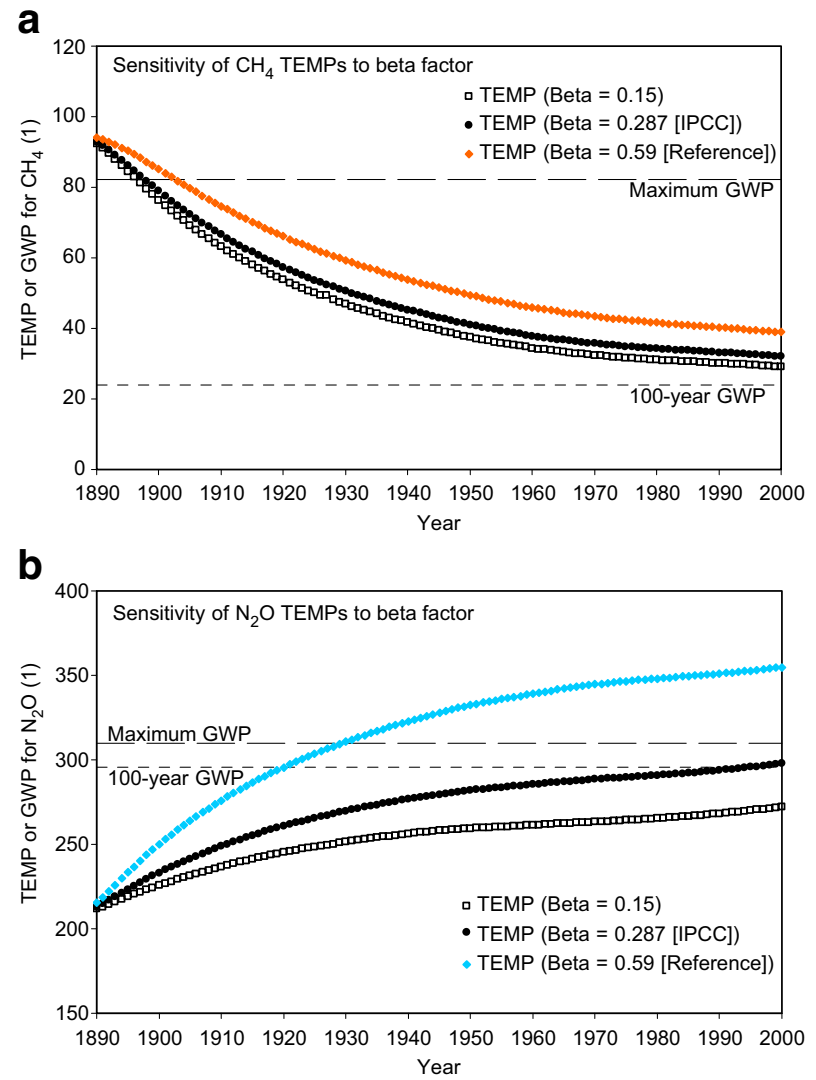

\section{$2.2 \mathrm{CH}_{4}$ and $\mathrm{N}_{2} \mathrm{O}$ lifetimes}

In the IPCC GWP calculations, the $\mathrm{CH}_{4}$ and $\mathrm{N}_{2} \mathrm{O}$ lifetimes adopt the adjustment times of 12 and 114 years, respectively (IPCC 2001, Table 6.7). In contrast, in the TEMP calculations, the $\mathrm{CH}_{4}$ lifetime with respect to $\mathrm{OH}$ depletion and $\mathrm{N}_{2} \mathrm{O}$ lifetimes use the baseline estimates of 8.5 and 114 years obtained from the ACC2 inversion, respectively (Tanaka et al. 2007, Table 3.2) and the $\mathrm{CH}_{4}$ lifetimes with respect to stratospheric loss and soil uptake are 120 and 160 years, respectively (IPCC 2001, p.248). The chemistry-transport models show the $\mathrm{CH}_{4}$ lifetime with respect to $\mathrm{OH}$ varying from 6.5 to 13.8 years (IPCC 2001, Table 4.3) and $\mathrm{N}_{2} \mathrm{O}$ lifetime from 97 to 137 years (IPCC 2001, Table 4.5). The total $\mathrm{CH}_{4}$ lifetime of 12 years assumed in the IPCC GWP calculation is equivalent to the $\mathrm{CH}_{4}$ lifetime with respect to $\mathrm{OH}$ depletion of 14.5 years when the $\mathrm{CH}_{4}$ lifetimes with respect to stratospheric loss and soil uptake are the IPCC estimates above.

We perform inversions by fixing the $\mathrm{CH}_{4}$ and $\mathrm{N}_{2} \mathrm{O}$ lifetimes at the values discussed above and then calculate TEMPs. Figure $7 \mathrm{c}, \mathrm{d}$ indicate that a longer lifetime of $\mathrm{CH}_{4}$ or $\mathrm{N}_{2} \mathrm{O}$ leads to a higher TEMP. This is due to the fact that an increase in the $\mathrm{CH}_{4}$ or $\mathrm{N}_{2} \mathrm{O}$ lifetime enhances the influence of the $\mathrm{CH}_{4}$ or $\mathrm{N}_{2} \mathrm{O}$ emissions to the temperature, resulting in a higher TEMP. 
Fig. 7 (continued)
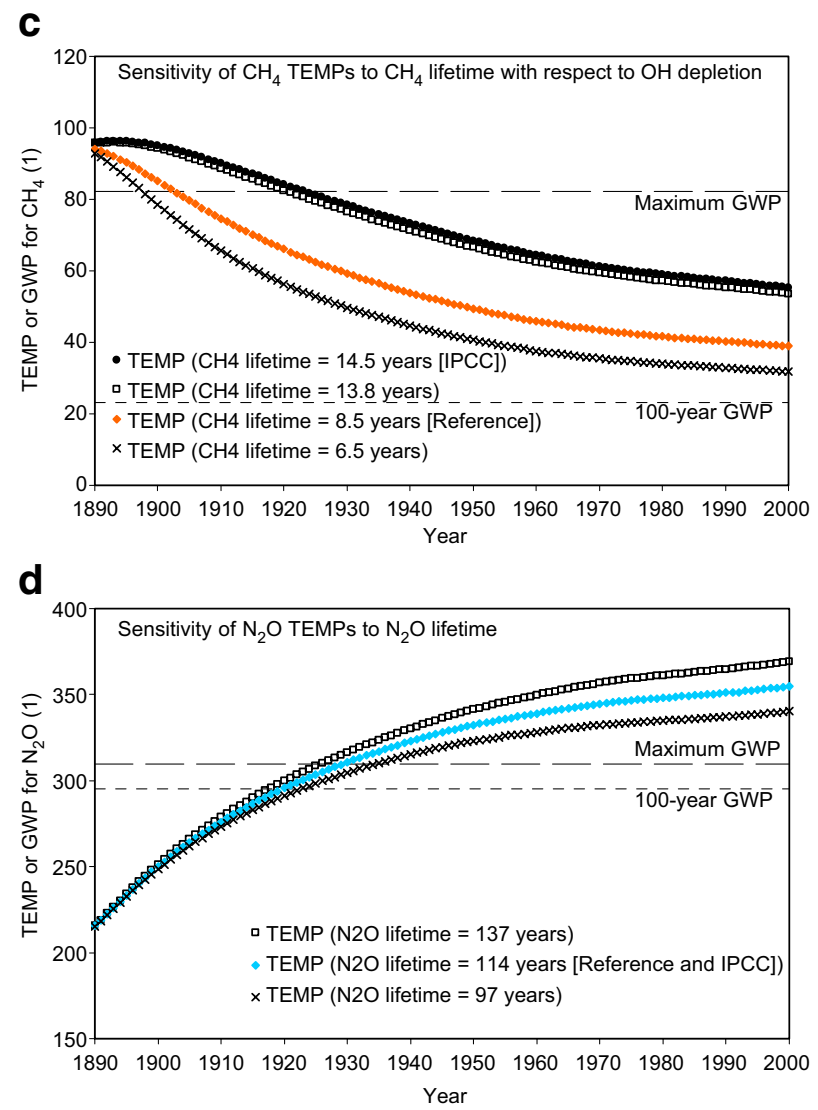

\subsection{Process simplifications}

The IPCC GWP calculations simplify the nonlinear dynamics in the background system. We investigate the implications of such simplifications in the following three parts:

1. The rate of ocean $\mathrm{CO}_{2}$ uptake in $\mathrm{ACC} 2$ saturates with increasing atmospheric $\mathrm{CO}_{2}$ concentration due to the shift in the thermodynamic equilibrium of the marine carbonate system. In contrast, the IPCC GWP calculation implicitly assumes a fixed equilibrium implied in the impulse response function for the Bern Carbon Cycle Model (Joos et al. 1996). To mimic the IPCC setting for the ocean $\mathrm{CO}_{2}$ uptake, we perform an inverse calculation by assuming a present Revelle factor (= 10.34 (Revelle and Munk 1977; Mackenzie and Lerman 2006, p.265)) throughout the historical period and compute TEMPs on the basis of such an inversion result.

2. A positive feedback for the $\mathrm{CH}_{4}$ concentration to its own lifetime occurs as a result of various chemical processes involving tropospheric $\mathrm{OH}$ (Seinfeld and Pandis 2006, pp.1048-1049). In contrast, there is a smaller but negative feedback for the $\mathrm{N}_{2} \mathrm{O}$ concentration to its own lifetime brought about by chemical 
Fig. 7 (continued)

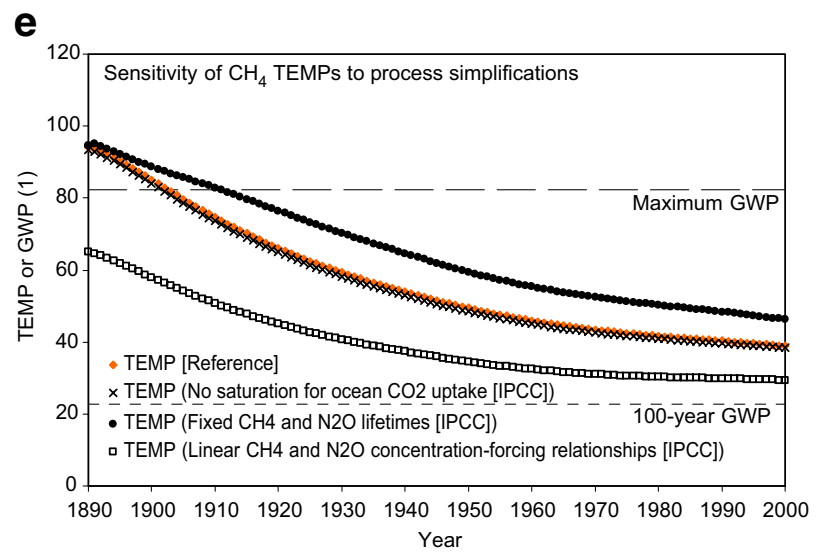

f

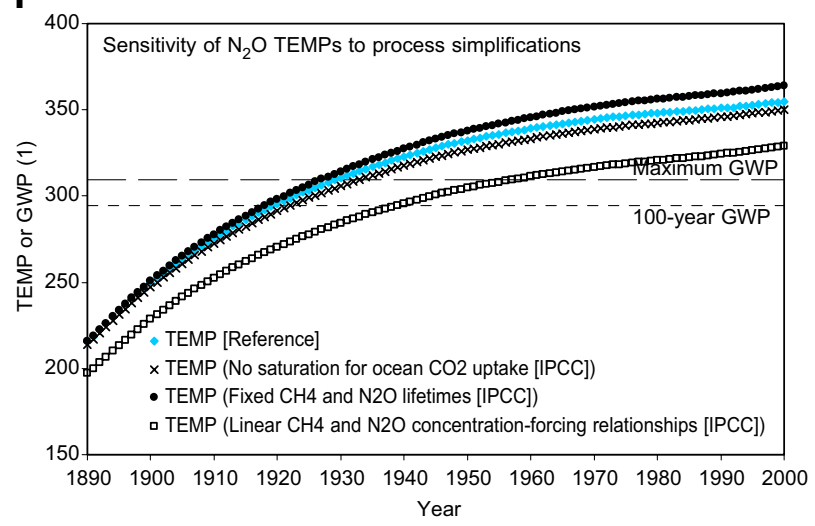

reactions in the $\mathrm{N}_{2} \mathrm{O}-\mathrm{NO}_{y}-\mathrm{O}_{3}$ system (Seinfeld and Pandis 2006, p.1048). Such concentration feedbacks to the lifetimes are accounted for in the IPCC GWP calculations as it uses the adjustment times for the lifetimes (IPCC 2001, Table 6.7). However, unlike ACC2 (Tanaka et al. 2007, Table 2.1), the IPCC GWP calculations assume the feedbacks as being fixed and independent of the concentrations. We hypothetically perform an inverse calculation by removing the concentration feedbacks to the lifetimes and then calculate TEMPs.

3. In $\mathrm{ACC} 2$, the $\mathrm{CH}_{4} / \mathrm{N}_{2} \mathrm{O}$ radiative forcing is formulated as a square root function of the $\mathrm{CH}_{4} / \mathrm{N}_{2} \mathrm{O}$ concentration to account for the saturation effect with an additional term to account for the overlap effect (IPCC 2001, Table 6.2; Tanaka et al. 2007, Table 2.1). In the IPCC GWP calculations, the saturation and overlap effects are kept constant, irrespective of the associated concentrations. To test the effect of such linearization, we perform an additional inverse calculation with linear concentration-forcing relationships using associated radiative efficiencies (IPCC 2001, Table 6.7) and then compute TEMPs.

The results of the three experiments are shown in Fig. 7e, f. It is indicated that the differences in the functional forms of the concentration-forcing relationships in particular go some way in explaining the disparity between $\mathrm{N}_{2} \mathrm{O}$ TEMPs and 
GWPs. The other two simplifications are not as important as the linearization of the concentration-forcing relationships to explain the departure of $\mathrm{N}_{2} \mathrm{O}$ GWPs from the TEMP. Thus, the linear assumptions in the concentration-forcing functional relationships in the IPCC GWP calculations is another factor (besides the low beta factor) explaining the fact that $\mathrm{N}_{2} \mathrm{O}$ GWP does not follow the temperature change history with any time horizon.

\section{References}

Aaheim A, Fuglestvedt JS, Godal O (2006) Costs savings of a flexible multi-gas climate policy. The Energy Journal. Multi-Greenhouse Gas Mitigation and Climate Policy Special Issue, pp 485-501

Ammann CM, Meehl GA, Washington WM, Zender CS (2003) A monthly and latitudinally varying volcanic forcing dataset in simulations of 20th century climate. Geophys Res Lett 30(12):1657. doi:10.1029/2003GL016875

Balmacela L, Krivova NA, Solanki SK (2007) Reconstruction of solar total irradiance since 1700 from the surface magnetic flux. Astron Astrophys 467:335-346

Bruckner T, Hooss G, Füssel H-M, Hasselmann K (2003) Climate system modeling in the framework of the Tolerable Windows Approach: the ICLIPS climate model. Clim Change 56:119-137

Crutzen PJ (2002) Geology of mankind. Nature 415:23

Eckaus RS (1992) Comparing the effects of greenhouse gas emissions on global warming. Energy J 13:25-35

Etheridge DM, Steele LP, Francey RJ, Langenfelds RL (1998) Atmospheric methane between 1000 $\mathrm{AD}$ and present: evidence of anthropogenic emissions and climatic variability. J Geophys Res 103(D13):15979-15993

Fankhauser S (1995) Valuing climate change: the economics of the greenhouse. EarthScan, London, $176 \mathrm{pp}$

Friedlingstein P, Fung I, Holland E, John J, Brasseur G, Erickson D, Schimel D (1995) On the contribution of $\mathrm{CO}_{2}$ fertilization to the missing biospheric sink. Glob Biogeochem Cycles 9:541-556

Friedlingstein P, Cox P, Betts R, Bopp L, von Bloh W, Brovkin V, Cadule P, Doney S, Eby M, Fung I, Bala G, John J, Jones C, Joos F, Kato T, Kawamiya M, Knorr W, Lindsay K, Matthews HD, Raddatz T, Rayner P, Reick C, Roeckner E, Schnitzler K-G, Schnur R, Strassmann K, Weaver AJ, Yoshikawa C, Zeng N (2006) Climate-carbon cycle feedback analysis: results from the C4MIP model intercomparison. J Climate 19:3337-3353

Fuglestvedt JS, Berntsen TK (1999) A simple model for scenario studies of changes in global climate. CICERO Working Paper 1999:2, University of Oslo, 59 pp

Fuglestvedt JS, Berntsen TK, Godal O, Skodvin T (2000) Climate implications of GWP-based reductions in greenhouse gas emissions. Geophys Res Lett 27(3):409-412

Fuglestvedt JS, Berntsen TK, Godal O, Sausen R, Shine KP, Skodvin T (2003) Metrics of climate change: assessing radiative forcing and emission indices. Clim Change 58:267-331

Gifford RM (1980) Carbon storage by the biosphere. In: Pearman GI (ed) Carbon dioxide and climate. Australian Academy of Science, Canberra, pp 167-181

Godal O, Fuglestvedt J (2002) Testing 100-year global warming potentials: impacts on compliance costs and abatement profile. Clim Change 52:93-127

Hansen J, Sato M (2004) Data sets used in GISS 2004 GCM. http://www.giss.nasa.gov/data/simodel/ ghgases/GCM.html

Hooss G (2001) Aggregate models of climate change: development and applications. PhD dissertation, Hamburg Universität, 113 pp. http://www.schoepfung-und-wandel.de/

Hooss G, Voss R, Hasselmann K, Maier-Reimer E, Joos F (2001) A nonlinear impulse response model of the coupled carbon cycle-climate system (NICCS). Clim Dyn 18:189-202

IPCC (1990) Climate change: the intergovernmental panel on climate change scientific assessment. In: Houghton JT, Jenkins GJ, Ephraums JJ (eds) Cambridge University Press, Cambridge, United Kingdom and New York, NY, USA, 364 pp

IPCC (2001) Climate change 2001: the scientific basis. Contribution of working group I to the third assessment report of the intergovernmental panel on climate change. In: Houghton JT, Ding Y, Griggs DJ, Noguer M, van der Linden PJ, Dai X, Maskell K, Johnson CA (eds) Cambridge University Press, Cambridge, United Kingdom and New York, NY, USA, 881 pp 
IPCC (2005) IPCC special report on safeguarding the ozone layer and the global climate system: issues related to hydrofluorocarbons and perfluorocarbons. Cambridge University Press, Cambridge, United Kingdom and New York, NY, USA, 486 pp

IPCC (2007) Climate change 2007: the physical science basis. contribution of working group I to the fourth assessment report of the intergovernmental panel on climate change. In: Solomon $S$, Qin D, Manning M, Chen Z, Marquis M, Averyt KB, Tignor M, Miller HL (eds) Cambridge University Press, Cambridge, United Kingdom and New York, NY, USA, 996 pp

Johansson DJA, Persson UM, Azar C (2006) The cost of using global warming potentials: analyzing the trade off between $\mathrm{CO}_{2}, \mathrm{CH}_{4}$ and $\mathrm{N}_{2} \mathrm{O}$. Clim Change 77:291-309

Jones PD, Briffa KR, Barnett TP, Tett SFB (1998) Millennial temperature reconstructions. IGBP PAGES/world data center-A for paleoclimatology data contribution series \#1998-039. NOAA/NGDC Paleoclimatology Program, Boulder CO, USA

Jones PD, Parker DE, Osborn TJ, Briffa KR (2006) Global and hemispheric temperature anomalies-land and marine instrumental records. In: Trends: a compendium of data on global change. Carbon Dioxide Information Analysis Center, Oak Ridge National Laboratory, U.S. Department of Energy, Oak Ridge, Tenn., U.S.A.

Joos F, Bruno M, Fink R, Siegenthaler U, Stocker TF (1996) An efficient and accurate representation of complex oceanic and biospheric models of anthropogenic carbon uptake. Tellus 48B:397-417

Joos F, Prentice C, Sitch S, Meyer R, Hooss G, Plattner G-K, Gerber S, Hasselmann K (2001) Global warming feedbacks on terrestrial carbon uptake under the intergovernmental panel on climate change (IPCC) emission scenarios. Glob Biogeochem Cycles 15:891-907

Kandlikar M (1996) Indices for comparing greenhouse gas emissions: integrating science and economics. Energy Econ 18:265-281

Kohlmaier GH, Brohl H, Siré EO, Plốchl M, Reville R (1987) Modelling stimulation of plants and ecosystem response to present levels of excess atmospheric $\mathrm{CO}_{2}$. Tellus 39B:155-179

Kriegler E (2005) Imprecise probability analysis for integrated assessment of climate change. $\mathrm{PhD}$ dissertation, Potsdam Universität, 258 pp. http://www.pik-potsdam.de/ kriegler/

Mackenzie FT, Lerman A (2006) Carbon in the geobiosphere: earth's outer shell. Springer, Dordrecht, The Netherlands, $402 \mathrm{pp}$

Maier-Reimer E, Hasselmann K (1987) Transport and storage of $\mathrm{CO}_{2}$ in the ocean-an inorganic ocean-circulation carbon cycle model. Clim Dyn 2:63-90

Mann ME, Jones PD (2003) Global surface temperatures over the past two millennia. Geophys Res Lett 30(15):1820. doi:10.1029/2003GL017814

Manne AS, Richels RG (2001) An alternative approach to establishing trade-offs among greenhouse gases. Nature 410:675-677

Masarie KA, Langenfelds RL, Allison CE, Conway TJ, Dlugokencky EJ, Francey RJ, Novelli PC, Steele LP, Tans PP, Vaughn B, White JWC (2001) NOAA/CSIRO flask intercomparison project: a strategy for directly assessing consistency among atmospheric measurements made by independent laboratories. J Geophys Res 106(D17):20445-20464

Millero FJ (1995) Thermodynamics of the carbon dioxide system in the oceans. Geochim Cosmochim Acta 59:661-677

Millero FJ, Graham TB, Huang F, Bustos-Serrano H, Pierrot D (2006) Dissociation constants of carbonic acid in seawater as a function of salinity and temperature. Mar Chem 100:80-94

O'Neill BC (2000) The jury is still out on global warming potentials. Clim Change 44:427-443

O'Neill BC (2003) Economics, natural science, and the costs of global warming potentials. Clim Change 58:251-260

O'Neill BC, Oppenheimer M, Gaffin SR (1997) Measuring time in the greenhouse. Clim Change 37:491-503

Reilly JM, Richards KR (1993) Climate change damage and the trace gas index issue. Environ Resour Econ 3:41-61

Reilly J, Prinn R, Harnisch J, Fitzmaurice J, Jacoby H, Kicklighter D, Melillo J, Stone P, Sokolov A, Wang C (1999) Multi-gas assessment of the Kyoto Protocol. Nature 401:549-555

Revelle R, Munk W (1977) The carbon dioxide cycle and the biosphere. In: Energy and climate, studies in geophysics. National Academy Press, Washington, D,C., US, pp 140-158

Schmalensee R (1993) Comparing greenhouse gases for policy purposes. Energy J 14:245-255

Seinfeld JH, Pandis SN (2006) Atmospheric chemistry and physics: from air pollution to climate change, 2nd edn. Wiley, New York, USA, 1203 pp

Shine KP, Fuglestvedt JS, Hailemariam K, Stuber N (2005) Alternatives to the global warming potential for comparing climate impacts of emissions of greenhouse gases. Clim Change 68:281-302 
Shine KP, Berntsen TK, Fuglestvedt JS, Skeie RB, Stuber N (2007) Comparing the climate effect of emissions of short- and long-lived climate agents. Philos Trans R Soc Lond A 365:1903-1914

Smith SJ (2003) The evaluation of greenhouse gas indices. Clim Change 58:261-265

Smith SJ, Wigley TML (2000) Global warming potentials: 1. climatic implications of emissions reductions. Clim Change 44:445-457

Tanaka K (2008) Inverse estimation for the simple earth system model ACC2 and its applications. $\mathrm{PhD}$ dissertation, Hamburg Universität, International Max Planck Research School on Earth System Modelling, Hamburg, 296 pp. http://www.sub.uni-hamburg.de/opus/volltexte/2008/3654/

Tanaka K, Kriegler E, Bruckner T, Hooss G, Knorr W, Raddatz T (2007) Aggregated carbon cycle, atmospheric chemistry, and climate model (ACC2): description of the forward and inverse modes. Reports on earth system science, no 40. Max Planck Institute for Meteorology, $188 \mathrm{pp}$. http://www.mpimet.mpg.de/wissenschaft/publikationen/erdsystemforschung.html

Tanaka K, Raddatz T, O'Neill BC, Reick C (2008) Is the climate sensitivity even more uncertain: Interim Report at International Institute for Applied Systems Analysis (IIASA) Ir-08-012. 79 pp. http://www.iiasa.aca.at/Admin/PUB/Documents/IR-08-012.pdf

Tarantola A (2005) Inverse problem theory and methods for model parameter estimation. Society for Industrial and Applied Mathematics (SIAM), Philadelphia, USA, 342 pp

Tjoelker MG, Oleksyn J, Reich PB (2001) Modelling respiration of vegetation: evidence for a temperature-dependent Q10. Glob Chang Biol 7:223-230

Tol RSJ (1999) The marginal costs of greenhouse gas emissions. Energy J 20:61-81

van Aardenne JA, Dentener FJ, Olivier JGJ, Klein Goldewijk CGM, Lelieveld J (2001) A 1 x 1 degree resolution dataset of historical anthropogenic trace gas emissions for the period 18901990. Glob Biogeochem Cycles 15(4):909-928

Wigley TML (1998) The Kyoto Protocol: $\mathrm{CO}_{2}, \mathrm{CH}_{4}$ and climate implications. Geophys Res Lett 25:2285-2288

World Meteorological Organization (WMO) (1999) Scientific assessment of ozone depletion: 1998. Global ozone research and monitoring project-report, no 44. Geneva, $650 \mathrm{pp}$

World Meteorological Organization (WMO) (2003) Scientific assessment of ozone depletion: 2002. Global ozone research and monitoring project—report, no 47. Geneva, $498 \mathrm{pp}$ 